\title{
The Effects of Mindfulness Meditation in Managing Chronic Pain: A Mini-Review
}

\author{
David Walker and Jodan Garcia* \\ Department of Physical Therapy, Georgia State University, USA
}

Submission: March 04, 2019; Published: April 26, 2019

*Corresponding author: Jodan Garcia, Department of Physical Therapy, Georgia State University, USA

\begin{abstract}
Pain is subjective and varies from person to person. The effects of pain often reach into all aspects of an individual's life, potentially disrupting their patterns of living. Chronic pain can be a difficult condition to manage. Individuals who suffer from chronic pain often feel every part of their lives by their pain, and these individuals often search for relief by trying multiple treatment options until one works. Various chronic pain treatments are commonly used to attempt to manage chronic pain include conservative approaches like physical therapy, pharmacological approaches such as topical or oral pain medications, and other modalities such as acupuncture. Due to the rise of deaths related to opioid use, non-pharmacological treatments like meditation and mindfulness programs are being investigated for their potential benefit for managing chronic pain. The purpose of this review is to investigate the efficacy of mindfulness programs for treating chronic pain. A review of literature was conducted from Cochrane, Pubmed, PEDro, Medline, National Rehabilitation Information Center, and Cinhal, and found positive results in the use of a mindfulness or meditation program in conjunction with other interventions in the treatment of chronic pain but mixed results in terms of using a mindfulness or meditation program as a lone intervention in the treatment of chronic pain.
\end{abstract}

Keywords: Chronic pain; Benign pain; Non-Specific pain; Musculoskeletal pain; Meditation; Mindfulness meditation; Non-pharmacological treatment

Abbreviations: SSD: Somatic Symptom Disorder; MBCT: Mindfulness Based Cognition Training; MBSR: Mindfulness Based Stress Reduction; MBIs: mindfulness-based interventions; RCT: randomized control trial; VAS: visual analogue scale; PCS: pain catastrophizing scale; NRS: numerical rating scales; CPAQ: chronic pain acceptance questionnaire; C-SOSI: Calgary Symptoms of Stress Inventory; MORE: MindfulnessOriented Recovery Enhancement; CES-D: Centre for Epidemiological Studies Depressive Scale; STAI: State-Trait Anxiety Inventory; MAAS mindfulness attention and awareness scale; MPI: Multidisciplinary Pain Intervention; HADS: Hospital Anxiety and Depression Scale

\section{Introduction}

Chronic pain is an increasingly common diagnosis in society affecting an estimated 25.3 million adults in 2012. Pain is defined by the International Association for the Study of Pain as, "An unpleasant sensory and emotional experience associated with actual or potential tissue damage or described in terms of such damage" [1] and chronic pain can be defined as pain that is present, "for at least half the days in a 6-month period" or that persists every day for a period of at least three months [2]. Chronic regional pain has been estimated to be present in 20 to $25 \%$ of the population and chronic widespread pain in $10 \%$ of the population, and patients with one form of chronic pain are more likely to develop another [1]. Despite its widespread prevalence the etiology of chronic pain is not well understood, and there is not a uniform treatment protocol that has been found to treat chronic pain.

There are a variety of types of chronic pain, and this review has chosen to focus on chronic pain that is musculoskeletal in nature. Chronic musculoskeletal pain syndromes can include conditions such as chronic headaches, temporomandibular disorder, fibromyalgia, irritable bowel syndrome, interstitial cystitis/irritable bladder, pelvic pain, and others [1]. The effects of these conditions are often limiting in terms of functionality and the ability to participate in daily activities. Often chronic pain also clusters with other symptoms such as fatigue, unrefreshing sleep, dyscognition, and mood disturbances [1]. These symptom clusters can further exasperate the pain or increase the risk of developing a mental health disorder such as depression.

The history of chronic pain recognition in the medical community and its associated psychological symptoms dates to the 1940 's. As soldiers were returning home from World War II, a case series on "psychogenic rheumatism" was published in 1946 [1]. Over the next few decades chronic pain underwent several name changes, culminating in its current DSM-V classification as either, "Somatic Symptom Disorder (SSD) with predominantly somatic complaints" or SSD with pain features." The underlying theme of all the different ways that chronic pain and its associated somatic symptoms have been thought of throughout the twentieth century is an, "inability to objectively verify symptoms expressed by the patient" [1]. This makes 
classification and thus treatment of chronic pain even more difficult.

A common and increasingly problematic treatment for chronic pain has been prescription pain medicine. Opioids specifically are effective at reducing symptoms of chronic pain, but can have devastating side-effects, especially if abused. Rates of opioid abuse are hard to estimate, but a large US healthcare system reported rates of outpatient long-term therapy abuse around $26 \%$. Other estimates have put abuse rates at $24 \%$ for commercially insured individuals and $20 \%$ for a Medicaid sample [3]. Opioid abuse has been linked to significantly increased morbidity and mortality [3]. The financial costs from opioid abuse are also significant. In 2007 alone the total cost of opioid abuse including workplace, healthcare, and criminal justice expenditures was estimated to be $\$ 55.7$ billion [3]. Additionally, abusers miss an estimated 2.2 days of work per month compared to 0.83 days per month for non-abusers [3]. Finally, when taking into consideration the estimated costs of lost productivity from individuals who die from opioid overdoses, and all the other associated costs incurred the total cost of the opioid epidemic can be estimated to be half a trillion dollars a year [3].

Due to these extraordinary costs alternative treatment methods to address chronic pain are being investigated. One of those treatment methods is mindfulness. Mindfulness has been defined as, "the awareness that emerges through paying attention on purpose, in the present moment, and non-judgmentally to the unfolding experience moment by moment" [4]. Mindfulness programs such as Mindfulness Based Cognition Training (MBCT) and Mindfulness Based Stress Reduction (MBSR) were originally designed to prevent depression in those at risk, and there is good evidence that mindfulness-based interventions (MBIs) can reduce current symptoms of depression, anxiety, and stress [4]. Due to the overlap of symptoms seen in patients with chronic pain and depression these programs may offer a method to address chronic pain.

The use of mindfulness as a treatment for musculoskeletal chronic pain is still relatively new, and there are a variety of mindfulness methods and program lengths that have been used to try to determine the effects of mindfulness on chronic pain. Due to a lack of evidence on the efficacy of this practice we conducted a review to determine the effectiveness of mindfulness programs as a treatment for musculoskeletal chronic pain.

\section{Methods}

Two authors independently conducted literature searches to identify studies on the effect of mindfulness practices in addressing chronic pain. The databases searched included Cochrane, Pubmed, PEDro, Medline, National Rehabilitation Information Center, and Cinhal. The following search terms were used: Mindfulness and Physical Therapy and Pain, Mindfulness and Rehabilitation and Pain, Meditation and Physical Therapy and Pain, and Meditation and Rehabilitation and Pain.

\section{Selection of Studies}

Seven studies met the inclusion criteria:

a) studies that were published in English.

b) randomized control trial (RCT); the study contained at least two groups where there are two different intervention groups or a meditation group and a wait-list control.

c) mindfulness intervention is being compared to another form of intervention or a control group to treat chronic pain.

d) the diagnosis is to treat chronic pain; either nonspecific, benign, or musculoskeletal pain (not cancerrelated).

e) At least one outcome measure tool is utilized to measure patient's progress.

Studies are excluded if they:

a) They were not written in English.

b) Non-RCT study.

c) Patient diagnosis is not a chronic pain condition or is pain resulting from cancer.

A total of 604 articles were originally found through the database searches. Of those, 584 were excluded based on review of the title and abstract. The remaining 20 articles were carefully evaluated against the inclusion and exclusion criteria through detailed readings. Thirteen of 20 articles were excluded, leaving 7 to be included in the final analysis.

\section{Results}

Seven studies examined various meditation programs and their effects on chronic pain intensity or severity scores compared to either a wait-list control group or another therapeutic intervention. Of the seven studies, five found statistically significant improvements in pain intensity scores following a meditation intervention protocol. Andersen and Vaegter [5] found that a 13-week mindfulness program significantly improved pain intensity scores on a 0-10 numerical rating scale, but not when compared to a wait list control group $(p=0.43)$ [5]. Garland et al. found a significant decrease in pain severity $(\mathrm{p}=0.038)$ following their meditation protocol using the BPI pain severity score [6]. Jeitler et al. [7] measured average neck pain intensity over the previous seven days at rest via a visual analogue scale (VAS) and found significantly reduced neck pain in their meditation group compared to an exercise group $(p=0.02)$ [7]. Jeitler [7] also measured pain at motion via VAS and found nonsignificant group differences $(p=0.13)$ [7]. Lee et al. [8] found that their modified Tai Chi protocol did not result in any statistically significant improvement in pain scores $(\mathrm{p}=0.06)$, although it approached significance [8]. Ussher et al. [9] found a significant reduction in pain severity within the meditation body scan group in the clinical setting $(\mathrm{p}=0.009)$ and as well as in the 
participants' own environments $(\mathrm{p}=0.004)$ as measured by the pain severity portions of BPI [9]. Wong et al. found that while both the mindfulness group and the multi-discipline psychoeducation groups saw statistically significant improvements in both pain intensity and pain related distress as measured by numerical rating scales (NRS), neither group saw statistically significant improvements in pain intensity compared to one another $(\mathrm{p}=0.882)$ [10].

They also found the MPI group saw a statistically significant improvement in pain-related distress when compared to the mindfulness group $(p=0.046)$ [10]. The authors also noted the improvements, although significant, were small and inconsistent, leading them to believe the intervention effects are weak. La Cour and Petersen used the Brief Pain Inventory and a pain scale component of the SF36 questionnaire to evaluate changes in pain and did not find a significant reduction in pain intensity for the Brief Pain Inventory $(\mathrm{p}=0.17$ ) or the SF36 pain component $(\mathrm{p}=.27)$ following their meditation protocol, however they did find a significant improvement in feelings of control over pain $(p=<0.01)[11]$.

Five of these studies also examined other facets of pain beyond just pain intensity. Andersen and Vaetger also examined pain catastrophizing using the pain catastrophizing scale (PCS) and chronic pain acceptance via the chronic pain acceptance questionnaire (CPAQ). They found a significant decrease in pain catastrophizing in the treatment group compared with baseline and a significant increase in chronic pain acceptance for both the treatment and wait-list control group when compared to baseline [5]. La Cour and Petersen did find significant increases in pain acceptance $(\mathrm{p}<0.01)$ using CPAQ and a significant increase in willingness to engage in activity despite pain $(p=0.07)$ from the SF36 questionnaire [11]. Garland et al. [6] found statistically significant decreases in functional interference of pain using the BPI pain functional interference scales in the meditation group compared to their control group $(\mathrm{p}=.003)$, and they found significantly lower levels of sympathetic arousal in meditation participants as compared to the support group $(\mathrm{p}=0.034)$ as determined from the 56-Item Calgary Symptoms of Stress Inventory (C-SOSI) [6]. Jeitler et al. [7] measured painrelated bothersomeness via VAS and a significant difference between groups favoring the meditation group for painrelated bothersomeness ( $p=0.031)$ [7]. Ussher et al. [9] found a significant decrease in pain-related distress in their meditation group compared to the control group using a standard clinical form in the clinical setting only $(\mathrm{p}=0.005)$ [9].

All seven studies also examined the effect of meditation protocols on psychological effects that are commonly associated with chronic pain. Andersen \& Vaegter [5] found that their integrated mindfulness program showed significant effects on reducing depression and anxiety as compared to the wait-list control group (Chi Square, $\mathrm{P}<0.007$ ) [5]. La Cour \& Petersen [11] found that their Mindfulness-Based Stressed Reduction (MBSR) protocol showed statistically significant improvements in general anxiety and depression scores ( $\mathrm{p}=0.01$ and $\mathrm{p}=0.05$ respectively) using the Hospital Anxiety and Depression Scale (HADS) [11]. La Cour \& Petersen [11] also found significant improvement in vitality $(\mathrm{p}=0.04)$ and a better mental quality of life $(\mathrm{p}=0.02)$ using different components of the SF36 [11]. Garland et al. [6] state their Mindfulness-Oriented Recovery Enhancement (MORE) meditation protocol may lead to a significantly decreased relationship between the desire for the participants to use opioids and opioid misuse $(p=0.01)$ [6]. Garland et al. [6] found a significant lower desire for opioids among their meditation group as compared to the support group control $(\mathrm{p}=0.027)$ even after controlling for pain severity [7]. Garland et al. [6] also found a decrease in self-reported opioid misuse in both the meditation and support group control immediately following treatment but found a significantly greater proportion of individuals in the meditation group no longer met opioid use disorder criteria as compared to the support group control $(\mathrm{p}=0.05)$ [6].

Jeitler did not find any significant between group differences for stress ( $p=0.438)$, anxiety ( $p=0.848)$, or depression $(p=0.803)$ [7]. Lee et al. [8] found a statistically significant change in depression scores when comparing their modified Tai Chi protocol to a standard Physical Therapy intervention $(\mathrm{p}=0.03)$ [8]. Ussher et al. [9] measured subjects' perceived social functioning via BPI and found a significant difference favoring their meditation group over the control group in the clinic setting only ( $\mathrm{p}=0.036)$, but they found no significant difference between groups with regard to perceived ability to perform daily activities as measured by a standard clinical form in the clinic or in the subject's own environment [9]. Wong et al. [10] measured depressive symptoms using a validated Chinese version of the Centre for Epidemiological Studies Depressive Scale (CES-D) and anxiety using a validated Chinese version of the State-Trait Anxiety Inventory (STAI) and found no significant differences in depressive or anxiety scores between the meditation group and the multidisciplinary pain intervention group [10].

Finally, two of the studies examined whether the mindfulness programs subjects experienced led to an increased level of mindfulness. Andersen \& Vaegter [5] used the mindfulness attention and awareness scale (MAAS) and did not find any significant changes in levels of mindfulness for their treatment group or control group but did find that the treatment group saw an increase in mindfulness scores while the control group saw a decrease in mindfulness scores [5]. Ussher et al. [9] did not find a significant change in any of the mindfulness measures they examined in the clinic or the subject's own environment [9].

\section{Discussion}

One challenge of evaluating the effectiveness of mindfulness as an intervention to treat chronic pain is that mindfulness programs vary and RCT mindfulness studies that follow a 
standardized program are not easily available in literature. For instance, there were five different mindfulness protocols utilized in experimental groups varied across the seven included studies: two standardized MBSR programs, one non-standardized MBSR program, one Cognitive Behavior with Integrated Mindfulness Meditation Program (CBTm), one MORE program, one Tai Chi protocol, and one Joyti Meditation program. This variety of programs makes it difficult to definitively conclude whether mindfulness is an effective intervention for chronic pain because it is hard to evaluate differences in effectiveness between mindfulness programs.

Additionally, another variable to examine in the included studies is whether the mindfulness programs are more effective than comparison interventions. Within the seven included studies there were multiple comparison interventions used, ranging from three wait-list controls, one exercise intervention, one Physical Therapy protocol, one Multidisciplinary Pain Intervention (MPI), and one support group. Thus, only four of the studies utilized a true intervention comparison such as an exercise protocol, Physical Therapy, MPI, or a support group. Within those four studies, only two demonstrated that mindfulness programs were significantly more effective than the comparison intervention at reducing pain. This again makes it more difficult to conclude whether mindfulness is an effective intervention for chronic pain.

Finally, in a broader sense mindfulness research is trending towards including mindfulness as one aspect of a multidisciplinary approach to treat conditions like pain, stress, and workplace burnout as opposed to a stand-alone intervention. Mindfulness has shown some promise as an intervention to treat stress and chronic pain, but it is likely that in the future mindfulness will be utilized in concert with other approaches. This may make reviews of this nature more difficult to complete in the future due to the intertwined nature of mindfulness and other intervention protocols, but overall patient outcomes may be better.

\section{Conclusion}

Our findings suggest that it is difficult to conclude a mindfulness intervention alone can reduce chronic pain; however, this does not mean mindfulness interventions are not beneficial in chronic pain treatment. The more encouraging results from our analysis indicate that a mindfulness protocol in conjunction with other interventions may be more effective in helping reduce chronic pain and the psychological deficits that occur concurrently with chronic pain than a mindfulness intervention alone.

Table 1: Description of Included Studies.

\begin{tabular}{|c|c|c|c|c|}
\hline & Subjects & $\begin{array}{l}\text { Experimental } \\
\text { Intervention }\end{array}$ & $\begin{array}{l}\text { Control or Comparison } \\
\text { Intervention }\end{array}$ & Outcome Measurements \\
\hline $\begin{array}{l}\text { Andersen } \\
\text { et al. [5] }\end{array}$ & $\begin{array}{l}N=125 ; n=80 \text { CBT } m, n \\
=45 \text { matched waiting list }\end{array}$ & $\begin{array}{l}\text { CBT m Program once per } \\
\text { week for } 2.5 \text { hours for } 13 \\
\text { weeks }\end{array}$ & $\begin{array}{l}\text { Matched wait list for } \\
\text { control }\end{array}$ & $\begin{array}{c}\text { Pain intensity, Depression and anxiety, } \\
\text { Pain catastrophizing, Level of mindfulness, } \\
\text { Acceptance }\end{array}$ \\
\hline $\begin{array}{l}\text { la Cour et } \\
\text { al. [11] }\end{array}$ & $\begin{array}{c}\mathrm{N}=109 ; \mathrm{n}=54 \text { meditation } \\
\text { group, } \mathrm{n}=55 \text { waiting list } \\
\text { control }\end{array}$ & $\begin{array}{c}\text { Standard MBSR Protocol } \\
\text { for one } 3 \text { - hour session per } \\
\text { week over } 8 \text { weeks }\end{array}$ & Wait List Control & $\begin{array}{l}\text { Pain measures, Physical function, Mental } \\
\text { function, Pain acceptance, Quality of life }\end{array}$ \\
\hline $\begin{array}{l}\text { Garland et } \\
\text { al. [6] }\end{array}$ & $\begin{array}{c}\mathrm{N}=115 ; \mathrm{n}=57 \text { MORE, } \mathrm{n}= \\
58 \text { support group }\end{array}$ & $\begin{array}{l}\text { MORE protocol for } 2 \text { hours } \\
\text { once a week for } 8 \text { weeks }\end{array}$ & $\begin{array}{l}\text { Support Support Group for } \\
2 \text { hours a week for } 8 \text { weeks }\end{array}$ & $\begin{array}{c}\text { Pain Severity, Pain Interference, Desire } \\
\text { for Opioids, Self-reported opioid abuse, } \\
\text { Nonreactivity, Reinterpretation of pain } \\
\text { Sensations, Reappraisal, Affective and } \\
\text { somatic symptoms of stress, Treatment } \\
\text { credibility }\end{array}$ \\
\hline $\begin{array}{l}\text { Jeitler et } \\
\text { al. [7] }\end{array}$ & $\begin{array}{c}\mathrm{N}=89 ; \mathrm{n}=45 \text { meditation } \\
\text { group, } \mathrm{n}=44 \text { exercise } \\
\text { group }\end{array}$ & $\begin{array}{l}\text { Jyoti Meditation } 1.5 \text { hours } \\
\text { once per week for } 8 \text { weeks }\end{array}$ & Exercise control group & $\begin{array}{l}\text { Mean group difference of change of } \\
\text { average neck pain intensity at rest }\end{array}$ \\
\hline $\begin{array}{l}\text { Lee et al. } \\
\quad[8]\end{array}$ & $\begin{array}{l}\mathrm{N}=86 ; \mathrm{n}=46 \text { Tai Chi } \\
\text { group } \mathrm{n}=40 \text { Physical } \\
\text { Therapy Group }\end{array}$ & $\begin{array}{l}\text { Tai Chi for } 1 \text { hours twice } \\
\text { per week for } 12 \text { weeks }\end{array}$ & $\begin{array}{l}\text { Physical Therapy for } 0.5 \\
\text { hours twice a week for } \\
6 \text { weeks, then a Home } \\
\text { Exercise Program } 0.5 \\
\text { hours four a week for } 6 \\
\text { weeks }\end{array}$ & $\begin{array}{c}\text { Mindfulness levels, Pain, Stiffness, and } \\
\text { Physical function }\end{array}$ \\
\hline $\begin{array}{l}\text { Ussher et } \\
\text { al. [9] }\end{array}$ & $\begin{aligned} \mathrm{N}= & 55 ; \mathrm{n}=27 \text { body scan, } \mathrm{n} \\
& =28 \text { control group }\end{aligned}$ & $\begin{array}{l}10 \text { min recording of } \\
\text { mindfulness body scan }\end{array}$ & $\begin{array}{l}\text { 10-minute recording of a } \\
\text { natural history text }\end{array}$ & $\begin{array}{l}\text { Pain serverity, Pain-related distress, } \\
\text { percevied ability to perform daily } \\
\text { acitivites, perceived social functioning }\end{array}$ \\
\hline $\begin{array}{l}\text { Wong et al. } \\
\quad[10]\end{array}$ & $\begin{array}{l}\mathrm{N}=100 ; \mathrm{n}=51 \text { MBSR } \\
\text { group, } \mathrm{n}=49 \text { MPI group }\end{array}$ & $\begin{array}{l}\text { Standard MBSR Protocol } \\
\text { for one } 2.5 \text { - hour session } \\
\text { per week over } 8 \text { weeks } \\
\text { with one } 7 \text { hour «retreat» } \\
\text { session }\end{array}$ & $\begin{array}{c}\text { Multidisciplinary Pain } \\
\text { Intervention strategy of } 8 \\
\text { weekly } 2.5 \text {-hour groups } \\
\text { sessions }\end{array}$ & Pain intensity, Pain-related distress \\
\hline
\end{tabular}




\section{References}

1. Nahin RL (2015) Estimates of Pain Prevalence and Severity in Adults: United States, 2012. J Pain 16(8): 769-780.

2. Crofford, Leslie J (2015) Chronic Pain: Where the Body Meets Pain Transactions of the Amewrican Clinical and Climatological Association 126: 167-183.

3. Kaye AD, Jones MR, Kaye AM, Ripoll JG, Galan V et al. (2017) Prescription Opioid Abuse in Chronic Pain: An Updated Review of Opioid Abuse Predictors and Strategies to Curb Opioid Abuse: Part 1. Pain Physician 20(2S): S93-S109.

4. Lever Taylor B, Cavanagh K, Strauss C (2016) The Effectiveness of Mindfulness-Based Interventions in the Perinatal Period: A Systematic Review and Analysis. PloS one 11(5): e0155720.

5. Andersen TE, Vægter HB (2016) A 13-Weeks Mindfulness Based Pain Management Program Improves Psychological Distress in Patients with Chronic Pain Compared with Waiting List Controls. Clin Pract Epidermiol Ment Health 12: 49-58.

6. Garland EL, Manusov EG, Froeliger B, Kelly A, Williams JM et al. (2014) Mindfulness-Oriented Recovery Enhancement for Chronic Pain and

DOI: 10.19080/JYP.2019.07.555709
Prescription Opioid Misuse: Results from an Early-Stage Randomized Controlled Trial. Journal of Consulting and Clinical Psychology 82(3): 448-459.

7. Jeitler, Michael et al. (2015) Effectiveness of Jyoti Meditation for Patients with Chronic Neck Pain and Psychological Distress - A Randomized Controlled Clinical Trial. The Journal of Pain 16(1): 77-86.

8. Lee AC, Harvey W, Wong JB, Price LL, Han X, et al. (2017) Effects of Tai Chi versus Physical Therapy on Mindfulness in Knee Osteoarthritis. Mindfulness 8(5): 1195-1205.

9. Ussher M, Spatz A, Copland C, Nicolaou A, Cargill A (2014) Immediate Effects of a Brief Mindfulness-Based Body Scan on Patients with Chronic Pain. J Behav Med 37(1): 127-134.

10. Wong SY, Chan FW, Wong RL, Chu MC, Kitty Lam YY, et al. (2011) Comparing the Effectiveness of Mindfulness-based Stressed Reduction and Multidisciplinary Intervention Programs for Chronic Pain: A Randomized Comparative Trial. The Clinical Journal of Pain 27(8): 724-732.

11. La Cour AP, Petersen M (2015) Effects of Mindfulness Meditation on Chronic Pain: A Randomized Controlled Trial. Pain Medicine 16(4): 641-652.

Your next submission with Juniper Publishers
will reach you the below assets
- Quality Editorial service
- Swift Peer Review
- Reprints availability
- E-prints Service
- Manuscript Podcast for convenient understanding
- Global attainment for your research
- Manuscript accessibility in different formats
( Pdf, E-pub, Full Text, Audio)
- Unceasing customer service
Track the below URL for one-step submission
https://juniperpublishers.com/online-submission.php

